\title{
Electrochromism or Water Splitting in Neutral Aqueous Solutions by a Metallo-Organic Assembly
}

\author{
Naveen Malik, ${ }^{[a]}$ Tatyana Bendikov, ${ }^{[b]}$ Michal Lahav, ${ }^{*[a]}$ and Milko E. van der Boom ${ }^{\star[a]}$
}

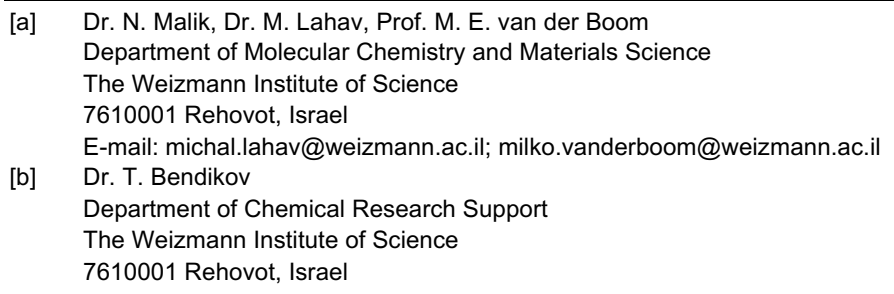

Supporting information for this article is given via a link at the end of the document.

\begin{abstract}
We describe two different functionalities of one metalloorganic film assembled on the surface of a transparent metal-oxide electrode. Two redox-active elements, electrochromic iron-polypyridyl complexes and catalytically-active palladium centers, operate by applying different potentials in aqueous solutions. The color of the material can be cycled 1500 times from dark purple to colorless by electrochemically addressing the $\mathrm{Fe}^{2+/ 3+}$ centers at 0.0-1.0 $\mathrm{V}$ (vs $\mathrm{Ag} / \mathrm{Ag}^{+}$). The differences between the transmittance of these two states is high: $\Delta T=52 \%$. Catalytic water oxidation can occur by palladium oxide particles that form in-situ by applying a higher potential (1.22-2.0 V vs $\left.\mathrm{Ag} / \mathrm{Ag}^{+}\right)$, resulting in the formation of dihydrogen and oxygen. The product output is stable for at least 7 hours in an aqueous electrolyte at $\mathrm{pH}=6.9$, with a Faradaic efficiency (FE) of $\sim 70 \%$.
\end{abstract}

Environmental sustainability requires a series of new functional materials for efficient catalysis, energy storage, conversion of solar energy into electricity, smart glass technology, carbon capture, and isolation, to name only a few. ${ }^{[1]}$ Renewable-based energy solutions (i.e., solar, wind) must be fully integrated with efficient energy storage and release systems. ${ }^{[2,3]}$ Electrocatalytic generation of hydrogen and oxygen from water is ideal because hydrogen can be used for energy storage, is transportable, and it can be used to process other storage chemicals such as liquid hydrocarbons. ${ }^{[4]}$ Molecular hydrogen is the ultimate clean fuel, since its combustion produces only water.

In 1982, the Meyer group reported ruthenium polypyridyl complexes as water-oxidation catalysts (WOCs). ${ }^{[5]}$ To date, many other molecular catalysts have been reported; however, several issues hamper their large-scale utilization, including poor reusability and the solubility of the catalysts, the need for sacrificial oxidants (e.g., ceric ammonium nitrate), and the harsh (acidic or alkaline) reaction conditions. ${ }^{[6-9]}$ Slow reaction rates, low catalyst stability, and high costs are other limitations. Low potentials are required to drive reactions with high current densities. Among various materials, transition metal oxides of ruthenium, iridium, manganese, cobalt, platinum, and their clusters are widely studied for electrocatalytic water splitting. ${ }^{[10-13]}$ For example, Negishi, $\mathrm{Pal}, \mathrm{Xu}, \mathrm{Lu}$, and others reported the use of $\mathrm{Pd}-\mathrm{Mn}_{3} \mathrm{O}_{4}$ and other catalytically active nanoclusters. ${ }^{[14-17]}$ In recent years, heterogenized catalysts on conducting surfaces have been shown to be chemically robust and reusable. ${ }^{[18-22]}$ The optimization of the catalytic process also includes searching for suitable materials that can immobilize and stabilize the clusters. Recently, the use of polyethyleneimine-modified reduced graphene (rGO) was found to support bimetallic gold-palladium nanoparticles for electrocatalysis. ${ }^{[22]}$ Metal-organic frameworks (MOFs) have also been shown to be promising electrocatalysts. ${ }^{[23]}$ MOFs have been dropcasted onto electrodes by use of a perfluorinated polymer containing sulphonic acid groups (Nafion) as a binder. Their high porosity allows the electrolyte and water molecules to access the catalytic sites. Farha and Hupp investigated MOFs based on cobalt formed by atomic layer deposition for electrochemical water oxidation under alkaline reaction conditions. ${ }^{[24]}$ Morris, Ott, and Fischer also reported the use of immobilized MOFs in electrochemical water oxidation. ${ }^{[25-27]}$

We have developed in our laboratory a series of nanoscale metallo-organic assemblies (MAs) that are redox-active, thermally stable, and highly porous. ${ }^{[28-39]}$ Coordination-based networks, comprising layers of polypyridyl complexes and metals salts, have been generated on transparent conductive substrates (TCOs) by Layer-by-Layer (LBL) assembly, automated spray-coating, or spin-coating. ${ }^{[29-31]}$ Whereas the polypyridyl complexes are the functional components, the metals salts (mainly palladium) function as a crosslinker by binding to the pyridyl moieties of polypyridyl complexes, generating 3D networks. The large structural versatility of our MAs has resulted in diverse and potentially useful functions: interlayers for efficient inverted bulkheterojunction solar cells, mimicry of logic gates and circuits (including flip-flops), memory elements, supercapacitors, antibacterial coatings, and directional electron transfer. ${ }^{[32-37]}$ Furthermore, these materials have excellent charge trapping and multistate electrochromic characteristics. ${ }^{[38,39]}$ Higuchi, Li, Kurth, Nishihara, Zenkina, Zharnikov, and others have studied related materials in attempting to achieve some of these functionalities. ${ }^{[40-}$ ${ }^{47]}$ However, the electrocatalytic properties of these MAs have not been explored.

We demonstrated both electrochromism in an aqueous electrolyte and electrocatalytic water splitting using a single functionalized electrode under mild reaction conditions (Scheme 1). The use of electrochromism in water is advantageous for developing laminated devices in which liquid gels are used. Such gels can contain volatile organic solvents and are prone to leakage. ${ }^{[30,31,39,42-47]}$ The MAs used here have been prepared by using fully automated LBL spin-coating. The system that we use is based on two functional components: a polypyridyl iron complex (1) and a common palladium dichloride salt (Scheme 1). The combination of three pyridyl moieties of the iron complex with the palladium(II) salt results in a dense, but still porous network on fluorine-doped tin oxide (FTO)-coated glass. The coordinatively 
saturated iron(II) complex has excellent electrochromic properties. It is deeply colored (purple) in the ground state and becomes highly transparent in the visible region upon one-electron oxidation, because of the unfavorable metal-to-ligand charge transfer (MLCT) in the formed iron(III) complex. This one-electron redox process is reversible. The palladium entity catalyzes water splitting, generating hydrogen and oxygen without the need for sacrificial materials. The interface engineering of the FTO electrodes is a multi-step process that can be conveniently carried out using fully automated spin-coating. The assembly of the different components on the surface is fast enough that the sequential steps can be carried out without significant delay times. The MA-modified electrode operates as an anode in two distinctly different electrochemical processes that occur in water under neutral conditions. In the electrochemical water splitting cell (EWSC), water is converted to oxygen at the MA-modified anode and hydrogen is converted at a platinium cathode (Scheme 1 and Figure 1).

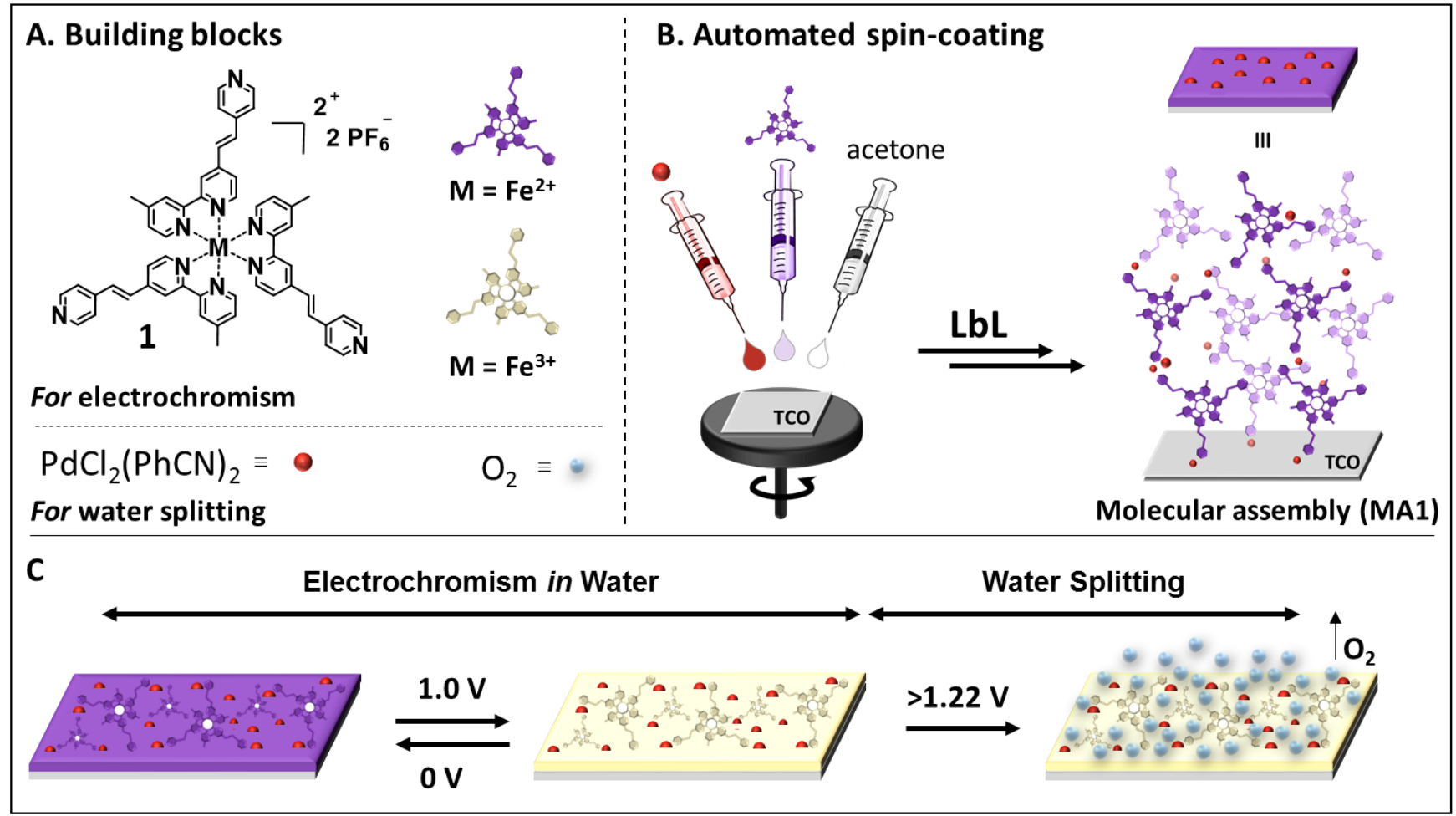

Scheme 1. (A) Molecular components used for the formation of the molecular assemblies (MAs). (B) Layer-by-Layer (LbL) spin-coating of MA1 on transparent conducting oxides (TCOs) by alternative deposition of solutions of $\mathrm{PdCl}_{2}(\mathrm{PhCN})_{2}$ and the metal complex 1 . (C) Electrochromic switching (0.0 V - $\left.1.0 \mathrm{~V}\right)$ or oxygen evolution (> $1.22 \mathrm{~V})$ of $\mathrm{MA1}$ in an aqueous electrolyte solution $\left(\mathrm{pH}=6.9 ; 0.1 \mathrm{M} \mathrm{LiClO}_{4}\right)$.

The MA was prepared by alternatively spin-coating solutions of $\mathrm{PdCl}_{2}(\mathrm{PhCN})_{2}(4.0 \mathrm{mM}, \mathrm{THF})$ and the polypyridyl iron complex (1: $0.6 \mathrm{mM}, \mathrm{DCM}: \mathrm{MeOH}=1: 1 \mathrm{v} / \mathrm{v})$ on FTO/glass $(2 \mathrm{~cm} \times 2 \mathrm{~cm})$. This fully automated deposition sequence was repeated 15 times and included washing with common organic solvents (Scheme 1A, B and see Supporting Information for details). Within $70 \mathrm{~min}$ this protocol resulted in an electrode having the desired electrochromic and catalytic properties. The electrodes are visually homogenously coated by the dark purple MA. Such assemblies prepared by LBL dip-coating, automatic spray-coating, or by manual spin coating are known to have excellent electrochromic properties in non-aqueous electrolyte solutions of acetonitrile. ${ }^{[29-31]}$ The number of depositions can used to control the color intensity of the films.

We used here a three-electrode cell configuration consisting of $\mathrm{MA} / \mathrm{FTO} / \mathrm{glass}$ as the working electrode (= anode) and $\mathrm{Pt}$ and
$\mathrm{Ag} / \mathrm{Ag}^{+}$wires as the counter (= cathode) and quasi-reference electrodes, respectively. An aqueous solution of $\mathrm{LiClO}_{4}(0.1 \mathrm{M})$ was used as an electrolyte with $\mathrm{pH}$ 6.9. Cyclic voltammetry (CV) measurements, recorded with a scan rate of $0.1 \mathrm{~V} / \mathrm{s}$, showed reversible redox processes at $0.69 \mathrm{~V}$ and $0.44 \mathrm{~V}$ with half wave redox potentials, $E_{1 / 2}$, of $0.56 \mathrm{~V}$ (versus $\mathrm{Ag} / \mathrm{Ag}^{+} ; 0.1 \mathrm{M} \mathrm{LiClO}{ }_{4} / \mathrm{H}_{2} \mathrm{O}$ ) (Figure 1B). These observations are indicative of a $\mathrm{Fe}^{2+/ 3+}$ redox couple. These redox processes occur under lower potentials, compared with the use of organic media. ${ }^{[48]} \mathrm{CV}$ was measured at different scan rates $(0.1-0.9 \mathrm{~V} / \mathrm{s})$. Clear exponential and linear correlations $\left(R^{2}>0.99\right.$ for all fits) were observed between the peak currents and scan rates and their square root (Figure S1). These correlations indicate that the redox processes are diffusion controlled. ${ }^{[30,31]}$ The diffusion coefficient, $D_{f}$, for MA1 is $\sim 3.7 \times$ $10^{-8} \mathrm{~cm}^{2} \cdot \mathrm{s}^{-1}$ for both the oxidation and reduction processes; it is calculated using the Randles-Sevcik equation. 


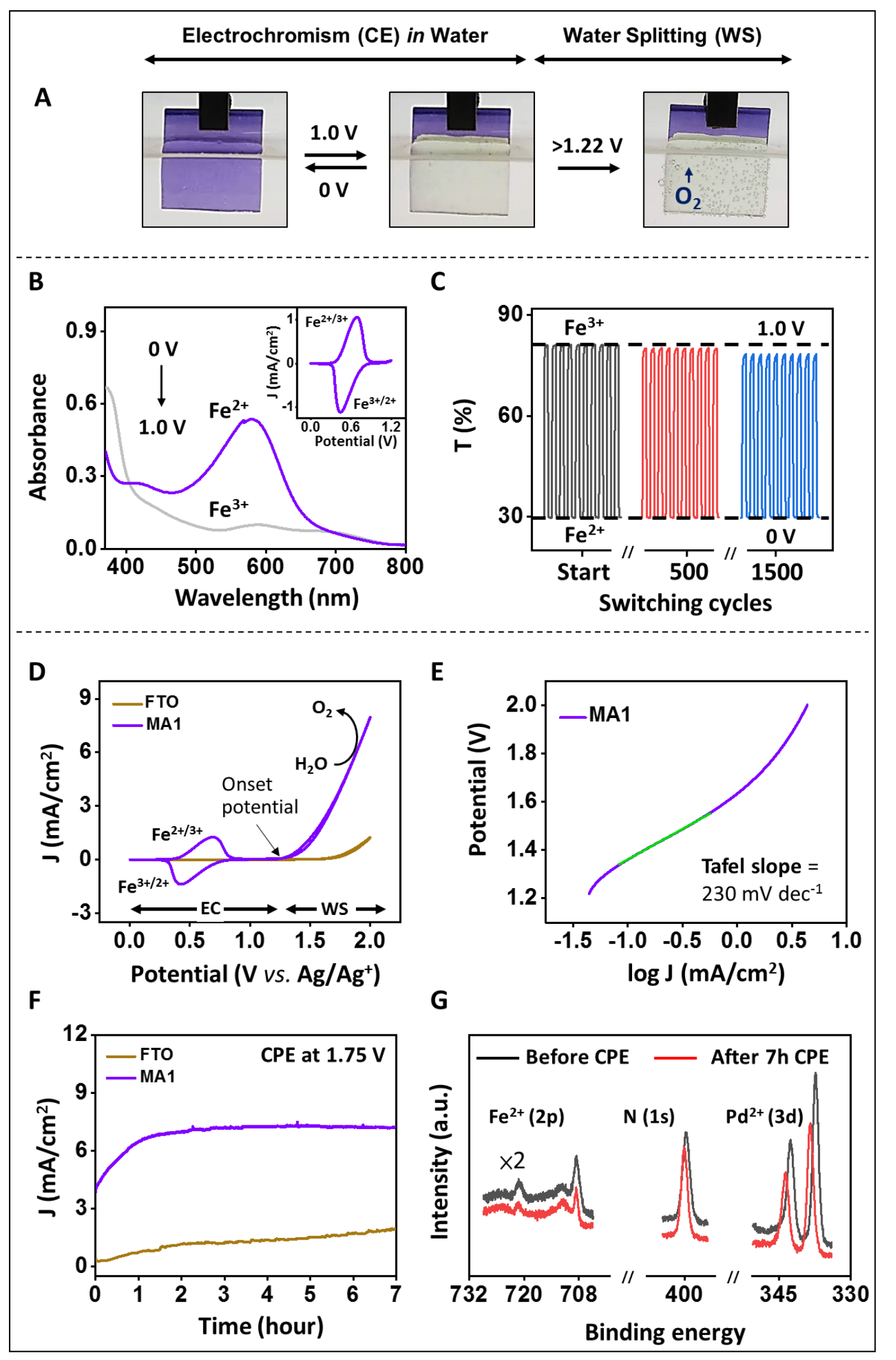

Figure 1. Electrochromic switching or oxygen evolution of MA1 in an aqueous solution. (A) Photographs of electrochromic switching and the formation of $\mathrm{O}_{2}$ via electrochemical water splitting. (B) Absorption spectra showing MA1 in the reduced (purple line) and oxidized state (grey line). Inset: Cyclic voltammograms (CV) measured at a scan rate of $0.1 \mathrm{~V} / \mathrm{s}$. (C) Spectroelectrochemical (SEC) measurements using double potential steps $0 \mathrm{~V}$ to $1.0 \mathrm{~V}\left(\lambda_{\text {max }}=575 \mathrm{~nm}\right)$. (D) CVs of MA1 and bare FTO/glass (scan rate $=0.1 \mathrm{~V} / \mathrm{s}$ ). Active substrate area: $1.1 \mathrm{~cm}^{2}$. (E) Tafel plot of MA1. (F) Controlled potential electrolysis (CPE) of MA1 and of bare FTO/glass. (G) X-ray photoelectron spectroscopy (XPS) spectra before (black) and after (red) electrolysis. The electrochemical experiments (A-F) were performed in an aqueous electrolyte solution $(\mathrm{pH}=6.9 ; 0.1 \mathrm{M} \mathrm{LiClO} 4)$ vs $\mathrm{Ag} / \mathrm{Ag}^{+}$. 
Spectroelectrochemical (SEC) measurements, recorded in the transmission mode, show the characteristic, broad Metal-toLigand Charge-Transfer (MLCT) band of the iron(II) complex at $\lambda_{\max } \approx 575 \mathrm{~nm}$ (Figure 1B). The MLCT band disappears upon the one-electron oxidation of the $\mathrm{Fe}^{2+}$ centers. This redox process is fully reversible and is accompanied by color-colorless-color transitions, which are clearly observable by the naked eye (Figure 1A). The high transparency of the MA, upon applying an oxidative current, indicates that all metal centers are electrochemically addressable at the applied scan rate.

To demonstrate the reversibility of this redox process in water, alternating potentials of $0.0 \mathrm{~V}$ and $1.0 \mathrm{~V}$ were applied with time intervals of $3 \mathrm{sec}$. while simultaneously montoring the optical absorbance of the MA at $\lambda_{\max }=575 \mathrm{~nm}$. These SEC measurements show that the maximum $\Delta \mathrm{T} \%$ of $\sim 52 \%$ is achieved in $\sim 0.9 \mathrm{~s}$ with $\geq 97 \%$ retention of the initial $\Delta \mathrm{T} \%$ for at least 1500 cycles (Figure 1C). The coloration efficiency is estimated to be $\sim 155 \mathrm{~cm}^{2} / \mathrm{C}$. Importantly, the electrochromic properties of such assemblies are not affected by the use of aqueous electrolyte solutions.

The above-demonstrated electrochromic functionality occurs at potentials that are lower than required for electrocatalytic water splitting. Upon increasing the potential higher than $1.22 \mathrm{~V}$, catalytic oxidation of water occurs, as indicated by the formation of bubbles on the surfaces of the colorless MA and the Pt wire (Figure 1A). The CV indicates oxygen evolution by the increase in the catalytic wave (Figure 1D). The catalytic current is significantly higher than that observed for bare FTO/glass. The corresponding Tafel plot shows a slope of $230 \mathrm{mV} \mathrm{dec}^{-1}$, which has been observed for electrocatalysis by MOFs (Figure 1E). ${ }^{[25-}$ ${ }^{26]}$ Electrolysis at a constant potential of $1.75 \mathrm{~V}\left(\mathrm{vs} \mathrm{Ag} / \mathrm{Ag}^{+}\right)$was characterized by a gradually increasing current density until a plateau was reached $(1.5 \mathrm{~h})$ and a current density of $\sim 7.2 \mathrm{~mA} / \mathrm{cm}^{2}$ was retained for an additional $5.5 \mathrm{~h}$ (Figure 1F). In addition, in this experiment, bare FTO/glass displayed a much lower (= fourfold) catalytic current under the same conditions. Gas chromatography (GC) analysis of the gas mixture in the headspace of the working compartment of the airtight electrochemical cell confirmed the formation of $537 \mu \mathrm{mol}$ of $\mathrm{H}_{2}$ after a $4.5 \mathrm{~h}$ reaction time $\left(\approx 268.5 \mu \mathrm{mol}\right.$ of $\left.\mathrm{O}_{2}\right)$. Controlled potential electrolysis (CPE) indicated that $148 \mathrm{C}$ of charge passed (the active surface area $=2.0 \mathrm{~cm}^{2}$ ), corresponding to a Faradaic efficiency (FE) of $70 \%$ (see Supporting Information for details). The turnover frequency (TOF) was estimated to be 0.12 $\mathrm{s}^{-1}$ (see Supporting Information for details). Anodization has been observed by others, ${ }^{[49,50]}$ indicating that an electrochemically driven process activates the catalyst. The initial anodization process of $\sim 1.5 \mathrm{~h}$ markedly improved the catalytic activity; it may be associated with structural changes within the films. ${ }^{[51]}$ Apparently, the catalytic current was not affected when the electrolyte solution was replaced after $6 \mathrm{~h}$ of electrolysis, and the experiment was continued with the same MA for another $8 \mathrm{~h}$ (Figure S3). CV measurements of the used electrolyte solutions (using bare FTO electrodes) do not reveal any redox-activity indicating that no functional material is being dissolved during CPE. Therefore, changes in the electrolyte solution or the buildup of $\mathrm{H}_{2}$ and $\mathrm{O}_{2}$ appear not to play a role in the efficiency of the catalytic process. Under the applied oxidative conditions in water, palladium oxide particles are expected to form, ${ }^{[52,53]}$ which has been confirmed by both scanning electron microscope (SEM) and CV measurements (vide infra).
To rigorously exclude the role of the polypyridyl iron complex (1) in water oxidation, we functionalized FTO electrodes with MA2 without this electrochromic component. A solution of $\mathrm{PdCl}_{2}(\mathrm{PhCN})_{2}(4.0 \mathrm{mM}, \mathrm{THF})$ and the vinylpyridyl ligand $\mathbf{L}(2.0$ $\mathrm{mM}, \mathrm{DCM}: \mathrm{MeOH}=1: 1 \mathrm{v} / \mathrm{v})$ were spin-coated on FTO/glass $(2 \mathrm{~cm}$ $\times 2 \mathrm{~cm}$ ) using fully automated spin-coating (see the supporting information for details and Figure S4A,B). This deposition sequence was repeated 15 times. UV-Vis spectroscopy shows a linear growth process, which was validated by plotting the absorption intensity at $\lambda_{\max }=333 \mathrm{~nm}$ versus the number of deposition cycles (Figure S4C). CV measurements recorded under the same conditions as for MA1 did not show the oxidation and reduction peaks that were attributed to complex 1 (Figure S4D). The observed onset potentials and catalytic currents are similar to the values observed with MA1. The Tafel slope of 217 $\mathrm{mV} / \mathrm{dec}$ and the current density from CPE at a constant applied potential of $1.75 \mathrm{~V}$ vs $\mathrm{Ag} / \mathrm{Ag}^{+}$for $7 \mathrm{~h}$ are also similar (Figure S5). Bubbles are clearly observable at the working and counter electrodes. GC analysis of the gas mixture revealed that $896 \mu \mathrm{mol}$ of $\mathrm{H}_{2}$ was produced $\left(\approx 448 \mu \mathrm{mol}\right.$ of $\mathrm{O}_{2}$ ) after $6.5 \mathrm{~h}$. CPE indicated that $264 \mathrm{C}$ of charge passed for an active surface area of $2.4 \mathrm{~cm}^{2}$, corresponding to a Faradaic efficiency (FE) of $67 \%$ (see the supporting information for details). An anodization process similar to the one observed for MA1 was observed here as well (Figure S4E). These observations confirm that the role of complex 1 is limited to electrochromism, and indicate that the palladium component catalyzes the water splitting for both MAs.

An intriguing question is whether palladium nanoparticles are formed that operate as a water splitting catalyst. Scanning electron microscopy (SEM) is an excellent tool for detecting palladium(0) nanoparticles as small as $\varnothing=8 \mathrm{~nm}$ in metallo-organic films. ${ }^{[52]}$ We use oxidative potentials; therefore, the formation of such metallic particles is not expected. ${ }^{[53]}$ However, it is known that palladium salts can form particles of palladium oxides under oxidative potentials in water. ${ }^{[3,54]}$ SEM imaging was performed on the two MAs before and after electrocatalysis for $7 \mathrm{~h}$ (Figure S710). These measurements show the presence of grainy, continuous coatings. After electrocatalysis, the presence of low amounts of particles has been oberved. Electrochromic cycling $(\times 1500)$ does not alter the texture and such particles were not oberved owing to the use of lower potentials (vide supra). EDS mapping indicated the presence of a homogeneous distribution of the expected elements; however, the resolution does not allow the composition of these particles to be elucidated (Figure S11). CV measurements of both MA1 and MA2 used for CPE measurements are consistent with the formation of palladium oxides (Figure S12). ${ }^{[53,54]}$ These CV measurements also show that the iron complexes (1) have undergone irreversible structural changes that resulted in loss of electrochemical reversibility. Regardless of these changes, it is remarkable that the films show relatively long catalytic stability without an appreciable leakage of material to the electrolyte solutions or changes in the surface texture.

We used X-ray photoelectron spectroscopy $(\mathrm{XPS})^{[30,31,55]}$ to study the elemental composition and the metal oxidation states of the upper $15-20 \mathrm{~nm}$ of both MAs before and after $7 \mathrm{~h}$ of electrolysis (Figure 1G, S4F, and S13). For MA1, two distinctive peaks attributed to the $2 \mathrm{p}$ orbitals of $\mathrm{Fe}^{2+}$ were observed at 708.6 $\mathrm{eV}\left(2 \mathrm{p}_{3 / 2}\right)$ and $721.2 \mathrm{eV}\left(2 \mathrm{p}_{1 / 2}\right)$. The binding energies did not change and no peaks are present that would indicate the formation of iron oxides. ${ }^{[55,56]}$ The overall oxidation state $(2+)$ of 
the palladium is also not affected, but the peaks of the $3 \mathrm{~d}$ orbitals are slighly shifted from $337.4 \mathrm{eV}\left(3 \mathrm{~d}_{5 / 2}\right)$ and $342.6 \mathrm{eV}\left(3 \mathrm{~d}_{3 / 2}\right)$ to $338.4 \mathrm{eV}\left(3 \mathrm{~d}_{5 / 2}\right)$ and $343.6 \mathrm{eV}\left(3 \mathrm{~d}_{3 / 2}\right)$, respectively (Figure 1G). These shifts may indicate an exchange of $\mathrm{Cl}^{-}$with $\mathrm{ClO}_{4}^{-}$, which is present in excess in the electrolyte solution (Figure S13). The amount of $\mathrm{Cl}^{-}$is significantly reduced and $\mathrm{ClO}_{4}^{-}$is observed. Changes in the oxidation state of the palladium centers during the reaction most likely facilitates this anion exchange; XPS analysis of MA2 reveals a similar effect (Figure S4, S13). The changes are also consistent with the formation of palladium hydroxides. ${ }^{[16]}$

There is a correlation between the catalytic performance and the number of deposited layers, as well as the similarity between MA1 and MA2, as determined from CV measurements. For both assemblies, the catalytic performance increases up to 10 layers, and subsequently levels off, upon increasing the thicknesses of the assemblies. This observation suggest that not all palladium centers are catalytically active for the MAs prepared by 15 deposition cycles, the electrochemical water splitting might occur only at the top layers. The EC experiments with MA1 indicate that all iron complexes are electrochemically addressable. It is know that small redox-probes in solution can be electrochemically addressed by electrodes surfaces coated by assemblies similar to the MAs used in this study. ${ }^{[50,57]}$ The similarity between the catalytic activities of MA1 and MA2 suggest the formation of similar amounts of the same catalysts.

This work highlights the electrochromic performance of metallo-organic films in an aqueous electrolyte without sacrificing switching stability and optical properties, compared with organic electrolytes. ${ }^{[29-31]}$ These findings can eliminate the use of volatile organics in sol-gel devices, and can serve as a new means to apply non-toxic chemicals in electrochromics and electronic devices based on metallo-organic films. Moreover, we have demonstrated that these films have orthogonal properties. ${ }^{[58]}$ Water can be split under mild (neutral) conditions by applying different potentials; this indicates that such materials are also promising for electrocatalysis. Mechanistically, the anodization process is consistent with the formation of nanosized particles that have been observed experimentally. Their exact structure is unknown; however, we expect the formation of palladium oxides under the applied oxidative conditions in water. ${ }^{[52,53]}$ We obtained evidence for the formation of such nanoparticles, and it was indicated that the water is split by these particles. Another interesting observation is the correlation between the catalytic performance and the number of deposited layers for both molecular assemblies. Although several factors most likely contribute to this effect, we noted that these structurally different assemblies have indistinguishable surface textures. It is most likely that the assembly-water interface plays a dominant role, which has been established for many heterogeneous catalysis applications. Importantly, this study shows that the performance of our MAs is comparable to that of MOFs on a surface. ${ }^{[24-27]}$ Interestingly, many other metal-organic assemblies reported by us $^{[28-39]}$ and others ${ }^{[40-47]}$ could be used for water splitting studies as well.

\section{Acknowledgements}

This research was supported by the Israel Science Foundation (ISF) and the Sustainability and Energy Research Initiative (SAERI). M.E.vdB. is the holder of the Bruce A. Pearlman
Professional Chair in Synthetic Organic Chemistry. The authors thank Sayan Kar and Dima Azaiza-Dabbah for their assistance in GC measurements and airtight catalytic cell design, respectively. The authors also thank Xiaomeng Sui and Vivek Singh for their help in the SEM measurements.

Keywords: electrochemical water oxidation - oxygen evolution reaction (OER) - bifunctional metallo-organic films • electrocatalysis $\cdot$ electrochromism

\section{References}

[1] M. G. Walter, E. L. Warren, J. R. McKone, S. W. Boettcher, Q. Mi, E. A. Santori, N. S. Lewis, Chem. Rev. 2010, 110, 6446-6473.

[2] N. Mariotti, M. Bonomo, L. Fagiolari, N. Barbero, C. Gerbaldi, F. Bella, Claudia Barolo, Green Chem., 2020, 22, 7168-7218.

[3] S. Park, Y. Shao, J. Liu, Y. Wang, Energy Environ. Sci. 2012, 5, 9331-9344.

[4] J. Zhu, L. Hu, P. Zhao, L. Y. S. Lee, K.-Y. Wong, Chem. Rev. 2020, 120, 851-918.

[5] S. W. Gersten, G. J. Samuels, T. J. Meyer, J. Am. Chem. Soc. 1982, 104, 4029-4030.

[6] S. M. Barnett, K. I. Goldberg, J. M. Mayer, Nat. Chem. 2012, 4, 498-502.

[7] B. Zhang, L. Sun, Chem. Soc. Rev. 2019, 48, 2216-2264.

[8] X. Sala, I. Romero, M. Rodrguez, L. Escriche, L., A. Llobet, Angew. Chem. Int. Ed. 2009, 48, 2842-2852.

[9] P. Li, R. Zhao, H. Chen, H. Wang, P. Wei, H. Huang, Q. Liu, T.i Li, X. Shi, Y. Zhang, M. Liu, X. Sun, Small 2019, 15, 1805103.

[10] M. W. Kanan, D. G. Nocera, Science 2008, 321, 1072-1075.

[11] Y. Gorlin, T. F. Jaramillo, J. Am. Chem. Soc. 2010, 132, 13612-13614.

[12] W. Schöfberger, F. Faschinger, S. Chattopadhyay, S. Bhakta, B. Mondal, J. A. A. W. Elemans, S. Müllegger, S. Tebi, R. Koch, F. Klappenberger, M. Paszkiewicz, J. V. Barth, E. Rauls, H. Aldahhak, W. G. Schmidt, A. Dey, Angew. Chem. 2016, 128, 2396-2401.

[13] M. Kondo, H. Tatewaki, S. Masaoka, Chem. Soc. Rev. 2021, 50, 6790-6831. [14] C. Ray, S. Dutta, Y. Negishi, T. Pal, Chem. Commun. 2016, 52, 6095-6098.

[15] N. Li, W.-Y. Xia, J. Wang, Z. -L. Liu, Q.-Y. Li, S. -Z. Chen, C. -W. Xu, X. -H. Lu, J. Mater. Chem. A 2015, 3, 21308-21313.

[16] F. Luo, Q. Zhang, X. Yu, S. Xiao, Y. Ling, H. Hu, L. Guo, Z. Yang, L. Huang, W. Cai, H. Cheng, Angew. Chem. Int. Ed. 2018, 57, 14862-14867.

[17] P. D. Morris, I. J. McPherson, M. A. Edwards, R. J. Kashtiban, R. I. Walton, P. R. Unwin, Angew. Chem. Int. Ed. 2020, 59, 19696 -19701.

[18] J. Li, C. A. Triana, W. Wan, D. P. A. Saseendran, Y. Zhao, S. E. Balaghi, S. Heidari, G. R. Patzke, Chem. Soc. Rev. 2021, 50, 2444-2485.

[19] K. E. deKrafft, C. Wang, Z. Xie, X. Su, B. J. Hinds, W. Lin, ACS Appl. Mater. Interfaces 2012, 4, 608-613.

[20] L. Wang, K. Fan, Q. Daniel, L. Duan, F. Li, B. Philippe, H. Rensmo, H. Chen, J. Sunc, L. Sun, Chem. Commun. 2015, 51, 7883-7886.

[21] H. Lei, C. Liu, Z. Wang, Z. Zhang, M. Zhang, X. Chang, W. Zhang, R. Cao, ACS Catal. 2016, 6, 6429-6437.

[22] G. Darabdhara, M. A. Amin, G. A. M. Mersal, E. M. Ahmed, M. R. Das, M. B. Zakaria, V. Malgras, S. M. Alshehri, Y. Yamauchi, S. Szunerits, R. Boukherrou, J. Mater. Chem. A 2015, 3, 20254-20266.

[23] S. Li, Y. Gao, N. Li, L. Ge, X. Bu, P. Feng, Energy Environ. Sci. 2021, 14, 1897-1927.

[24] C.-W. Kung, J. E. Mondloch, T. C. Wang, W. Bury, W. Hoffeditz, B. M. Klahr, R. C. Klet, M. J. Pellin, O. K. Farha, J. T. Hupp, ACS Appl. Mater. Interfaces 2015, 7, 28223-28230.

[25] P. M. Usov, S. R. Ahrenholtz, W. A. Maza, B. Stratakes, C. C. Epley, M. C. Kessinger, J. Zhu and A. J. Morris, J. Mater. Chem. A 2016, 4, 1681816823.

[26] S. Roy, Z. Huang, A. Bhunia, A. Castner, A. K. Gupta, X. Zou, S. Ott, J. Am. Chem. Soc. 2019, 141, 15942-15950.

[27] W. Li, S. Xue, S. Watzele, S. Hou, J. Fichtner, A. L. Semrau, L. Zhou, A. Welle, A. S. Bandarenka, R. A. Fischer, Angew. Chem. Int. Ed. 2020, 59, 5837-5843.

[28] G. de Ruiter, M. Lahav, M. E. van der Boom, Acc. Chem. Res. 2014, 47, 3407-3416. 
[29] L. Motiei, M. Lahav, D. Freeman, M. E. van der Boom, J. Am. Chem. Soc. 2009, 131, 3468-3469.

[30] N. E. Dov, S. Shankar, D. Cohen, T. Bendikov, K. Rechav, L. J. W. Shimon, M. Lahav, M. E. van der Boom, J. Am. Chem. Soc. 2017, 139, 11471 11481.

[31] N. Malik, N. E. Dov, G. de Ruiter, M. Lahav, M. E. van der Boom, ACS Appl. Mater. Interfaces 2019, 11, 22858-22868.

[32] L. Motiei, Y. Yao, J. Choudhury, H. Yan, T. J. Marks, M. E. van der Boom, A. Facchetti, J. Am. Chem. Soc. 2010, 132, 12528-12530.

[33] G. de Ruiter, L. Motiei, J. Choudhury, N. Oded, M. E. van der Boom, Angew. Chem. Int. Ed. 2010, 49, 4780-4783.

[34] G. de Ruiter, Y. H. Wijsboom, N. Oded, M. E. van der Boom, ACS Appl. Mater. Interfaces 2010, 2, 3578-3585.

[35] O. Eisenberg, M. Y. Algavi, H. Weissmann, J. Narevicius, B. Rybtchinski, M. Lahav, M. E. van der Boom, Adv. Mater. Interfaces 2020, 7, 2000718.

[36] M. Morozov, R. Carmeli, M. Lahav, M. E. van der Boom, ChemistrySelect 2017, 2, 577-582.

[37] R. Balgley, G. de Ruiter, G. Evmenenko, T. Bendikov, M. Lahav, M. E. van der Boom, J. Am. Chem. Soc. 2016, 138, 16398-16406.

[38] Y. Hamo, M. Lahav, M. E. van der Boom, Angew. Chem., Int. Ed. 2020, 59, 2612-2617.

[39] N. Malik, M. Lahav, M. E. van der Boom, Adv. Electron. Mater. 2020, 6, 2000407.

[40] S. Mondal, D. C. Santra, Y. Ninomiya, T. Yoshida, M. Higuchi. ACS Appl. Mater. Interfaces 2020, 12, 58277-58286.

[41] J. Zhang, J. Wang, C. Wei, Y. Wang, G. Xie, Y. Li, M. Li, Nat. Commun. 2020, 11, 2530.

[42] N. O. Laschuk, R. Ahmad, I. I. Ebralidze, J. Poisson, E. B. Easton, O. V. Zenkina, ACS Appl. Mater. Interfaces 2020, 12, 41749-41757.

[43] K. Takada, R. Sakamoto, S.-T. Yi, S. Katagiri, T. Kambe, H. Nishihara, J. Am. Chem. Soc. 2015, 137, 4681-4689

[44] P. C. Mondal, V. Singh, M. Zharnikov, Acc. Chem. Res. 2017, 50, 21282138.

[45] M. Schott, W. Szczerba, D. G. Kurth, Langmuir 2014, 30, 10721-10727.

[46] B. -B. Cui, J. -H. Tang, J. Yao, Y. -W. Zhong, Angew. Chem. Int. Ed. 2015, 54, 9192-9197.

[47] S. R. Jena, J. Choudhury, Chem. Commun. 2020, 56, 559-562.

[48] A. J. Bard, L. R. Faulkner Electrochemical Methods: Fundamentals and Applications 2nd ed.; John Wiley \& Sons: New York, 2001.

[49] D. K. Bediako, B. L. Kaiser, Y. Surendranath, J. Yano, V. K. Yachandra, D. G. Nocera, J. Am. Chem. Soc. 2012, 134, 6801-6809.

[50] Z. Luo, Sara M. -Sànchez, R. Nafria, G. Joshua, M. de la Mata, P. Guardia, C. Flox, C. M. -Boubeta, K. Simeonidis, J. Llorca, J. R. Morante, J. Arbiol, M. Ibáñez, A. Cabot, ACS Appl. Mater. Interfaces 2016, 8, 29461-29469.

[51] F. Li, L. Bai, H. Li, Y. Wang, F. Yua, L. Sun, Chem. Commun. 2016, 52, 5753-5756.

[52] M. Morozov, T.Bendikov, G. Evmenenko, P. Dutta, M. Lahav, M. E. van der Boom, Chem. Commun. 2016, 52, 2683-2686.

[53] V.C. Diculescu, A.-M. C. -Paquim, O. Corduneanu, A. M. O. -Brett, J. Solid State Electrochem. 2007, 11, 887-898.

[54] M. Villalba, M. L. Bossi, E. J. Calvo, Phys. Chem. Chem. Phys. 2015, 17, 10086-10092.

[55] Crist, B. V. A Review of XPS Data-Banks. XPS Rep. 2007, 1, 1-5.

[56] T. Yamashita, P. Hayes, Appl. Surf. Sci. 2008, 254, 2441-2449.

[57] A. L. Eckermann, D. J. Feld, J. A. Shaw, T. J. Meade, Coord. Chem. Rev. 2010, 1769-180

[58] S. Wang, Z. Xu, T. Wang, T.Xiao, X.-Yu Hu, Y.-Z. Shen, L. Wang, Nat. Commun. 2018, 9, 1737. 


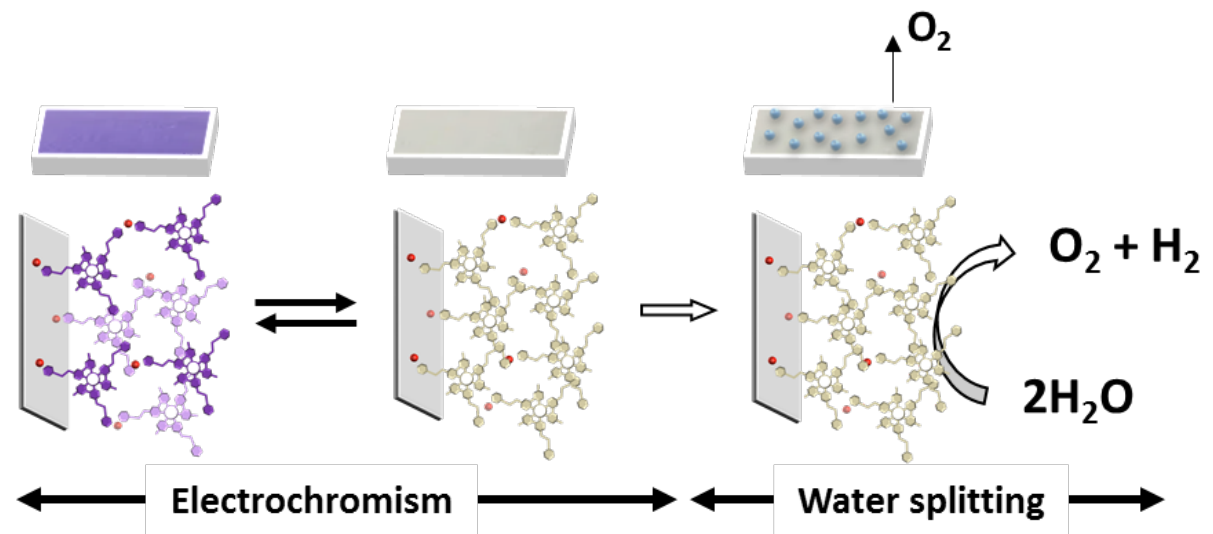

Two for One: Electrochromic complexes were reversibly active at low potentials. Whereas, the electrocatalytic component was activated at higher potentials using environmentally-friendly neutral aqueous conditions. 